\title{
Suppression of Rack-Storage Fires by Water
}

\author{
HONG-ZENG YU, JAMES L. LEE and HSIANG-CHENG KUNG \\ Factory Mutual Research Corporation \\ 1151 Boston-Providence Turnpike \\ Norwood, MA 02062
}

\section{ABSTRACT}

A series of large-scale fire suppression tests was conducted for two different commodities stored in steel racks of different heights, and were analyzed using a global heat balance model. In these tests, water was applied uniformly on top of the storage array at selected fire sizes to determine the fire suppressibility for a commodity at a given storage height. A fire suppression parameter was used to correlate the fire suppression results of these tests. The fire suppression parameter is a function of fuel density, fuel specific heat, ignition temperature, heat of combustion, burning rate, heat of pyrolysis, and water application rate. The data indicate that the combustible packaging and overall storage arrangement have significant impact on the magnitude of the critical water density for fire suppression.

KEYWORDS: water-based fire suppression.

\section{INTRODUCTION}

In 1984, Factory Mutual Research Corporation (FMRC) initiated a sprinkler research program, with the intent to develop an effective sprinkler protection for warehouse occupancies so that fire can be suppressed shortly after sprinkler operation to limit fire, smoke and water damages (1). A series of fire tests was conducted in this program to determine the required delivered densities (RDD) of water for fire suppression for the FMRC Standard flass II commodity and the Plastic commodity in rack storage configurations $(2)^{2}$. The Class II commodity consists of double triwall cartons lined with sheet metal, representing a low fire hazard commodity. The Plastic commodity is made of unexpanded polystyrene cups arranged in compartmented cartons, representing a high fire hazard commodity.

Fire suppression of solid fuels by water has attracted only limited jnterest thus far in the fire research community. Heskestad (3) and Rasbash $(4)$ reviewed the status of this subject in 1980 and 1986 , respectjyely. In the studies refated to the present investigation, Kung and $\mathrm{Hill}(5)$ and Tamanini $(6)$ studied extinguishment of wood crib fires by water in the 1970 's. Kung and Hill developed correlations between the following two ratios: 1) the ratio of mass consumed during water application versus the available mass at the beginning of water application, and 2) the ratio of water application rate versus the burning rate at the beginning of water application. Lee $(7)$ adopted the same ratios to correlate the test results of the Class II commodity stored in racks of different heights. However, this correlation is restricted to the Class II commodity. It is desirable to develop a generalized correlation for different commodities, storage 
heights, water application rates and fire sizes at the beginning of water application. This study used a global energy balance concept to identify a paraineter to correlate the fire suppression data of both the Class II and the Plastic commodities. This parameter takes into account the effects of commodity properties, packaging of commodity, storage arrangement and water application rate.

\section{FIRE SUPPRESSION EXPERIMENTS}

The experiments were conducted in the FMRC Test Center building located in West Glocester, Rhode Island. The building has an open floor plan of $61 \mathrm{~m} \mathrm{x}$ 76 m under one flat ceiling, which consists of two approximately equal test areas with ceiling heights of $7.14 \mathrm{~m}$ and $18.28 \mathrm{~m}$, respectively. The experiments were conducted in the area with the greater ceiling height. In the following, the tested commodities, storage arrangements, test apparatuses and the test procedure will be briefly described. Reference 2 provides detailed information about these experiments.

The FMRC Standard Class II Commodity and the FMRC Standard Plastic Commodity were used (2). A pallet load of the Standard Class I I Commodity consists of metal-lined double triwall cartons on a wood pallet. The outer carton measures $106.8 \mathrm{~cm} \times 106.8 \mathrm{~cm} \times 104.1 \mathrm{~cm}$ high and weighs $19.5 \mathrm{~kg}$; the inner carton measures $103.6 \mathrm{~cm} \times 103.6 \mathrm{~cm} \times 95.9 \mathrm{~cm}$ high and weighs $18.6 \mathrm{~kg}$. The metal liner, which has an open bottom, measures $96.5 \mathrm{~cm} \times 96.5 \mathrm{~cm} \times 94 \mathrm{~cm}$ high and weighs $22.2 \mathrm{~kg}$. The slatted wood pallet has dimensions of $106.8 \mathrm{~cm}$ $\mathrm{x} 106.8 \mathrm{~cm} \times 13.6 \mathrm{~cm}$ high and has a nominal weight of $23.4 \mathrm{~kg}$. As a result, each pallet load has a nominal gross weight of $83.7 \mathrm{~kg}$, of which about $74 \%$ is combustible. The FMRC Standard Plastic commodity comprises polystyrene cups in compartmented, single-wall, corrugated paper cartons. Eight such cartons are placed on a wood pallet to make a pallet load. In each $53.3 \mathrm{~cm}$ $\mathrm{x} 53.3 \mathrm{~cm} \times 50.8 \mathrm{~cm}$ high carton there are 125 compartments arranged in a $5 \times$ $5 \times 5$ matrix. Vertical and horizontal cardboard dividers about $0.4 \mathrm{~cm}$ thick are used to form the compartments. A $473 \mathrm{ml}$ capacity polystyrene cup is placed in each compartment. The weight of the polystyrene cups per carton is $3.7 \mathrm{~kg}$. The weight of an empty carton with dividers is $2.7 \mathrm{~kg}$. The wood pallet is the same as that used in the Class II commodity. The gross weight of a pallet load of the Standard Plastic commodity is thus $74.6 \mathrm{~kg}$, of which $40 \%$ is polystyrene cups, $29 \%$ is cartons and dividers, and $31 \%$ is the wood pallet.

A double-row steel rack was used to hold the commodities. The tested fuel arrays were two-pallet loads wide and two-pallet loads deep. The storage heights ranged from two tiers to four tiers for the Class I commodity, and from two tiers to five tiers for the Plastic commodity. Within each storage array, $0.15 \mathrm{~m}$ wide flue spaces were kept between the vertical surfaces of the pallet loads. In addition, $0.35 \mathrm{~m}$ and $0.37 \mathrm{~m}$ horizontal spaces were kept in between the consecutive tiers for the Class II and Plastic commodities, respectively. A typical four-tier high rack storage can be found in Refs. 2 and 7 .

A water applicator $(2,7)$ was supported $3.05 \mathrm{~cm}$ above the fuel array to deliver a pre-selected water application density directly on the top of the storage array. The water applicator consisted of eight parallel, doublejacketed, stainless steel pipes with eight spray nozzles along each pipe to form an $8 \times 8$ matrix of nozzles $30.5 \mathrm{~cm}$ apart. The water applicator was cooled by passing water through the annulus between the inner and outer pipes while the water for fire suppression was supplied via the inner pipes. 
Spray nozzles, manufactured by Spraying System Company and producing $60-$ degree full cone sprays, were used to deliver water to the fuel array in the calibrated flow rate range of 24 to 315 liters $/ \mathrm{min}$. The median volumetric drop size ranged from $1.1 \mathrm{~mm}$ to $2.8 \mathrm{~mm}$ for the nozzle operation conditions giving water flow rates in the above range. The water pressure was monitored at the upstream and downstream manifolds of the inner pipes of the water applicator using two pressure transducers (Honeywell Micro-Switch, Model 242PC). The total water flow rate supplied to these inner pipes was monitored using a rotameter.

The ignition source consisted of four cellucotton rolls $7.5 \mathrm{~cm}$ long and 7.5 $\mathrm{cm}$ in diameter, each soaked with $120 \mathrm{ml}$ of gasoline and wrapped in a polyethylene bag. The cellucotton rolls were placed near the central flue space of the fuel array at the bottom four corners of the lowest tier. A propane torch was used to ignite these cellucotton rolls.

When testing, the entire fuel array was placed at least $3.5 \mathrm{~m}$ under a Fire Products Collector (FPC) to collect the entire amount of exhaust gases released from the fire. The FPC is a large-scale calorimeter with an exhaust capacity of $30 \mathrm{~kg} / \mathrm{s}$ of air at room temperature ${ }^{(8)}$. The FPC was instrumented to monitor the gas temperature, gas flow rate and the concentrations of major combustion products $\left(\mathrm{CO}_{2}, \mathrm{CO}, \mathrm{O}_{2}\right.$ and total hydrocarbons) inside the FPC. Based on the gas flow rate and gas concentrations in the FPC, as well as the amplent condition, the total (chemical) heat release rate could be derived ${ }^{2}$.

In each test, the water applicator was activated to deliver a preselected flow rate on top of the fuel array when the heat release rate of the fire exceeded a predetermined value. The test was terminated when the rate of convective heat flow in the FPC dropped below $50 \mathrm{~kW}$ or the test time reached $30 \mathrm{~min}$., whichever came first. Data signals were scanned seven times per second using a data acquisition system. In each second the average of these seven readings for each channel was recorded.

\section{DATA ANALYSIS}

Table 1 presents a sample of the test conditions of the 98 RDD fire tests analyzed in this paper. The complete list of the test conditions is tabulated in Ref. 9. The water application densities on the top of the fuel array ranged from $4.48 \mathrm{~mm} / \mathrm{min}$ to $35.45 \mathrm{~mm} / \mathrm{min}$. The total heat release rate at water application was from $1100 \mathrm{~kW}$ to $8680 \mathrm{~kW}$.

For the fire suppression tests analyzed in this study, fire was started at the bottom of the center flue of the fuel array and spread upward rapidly in the vertical flue space. Before water application, the burning was primarily on the vertical surfaces of the flues. As water was applied to the top of the fuel array, it first covered the top surfaces of the fuel array and then cascaded downward along the vertical surfaces of the commodities. If the water application density was sufficiently high, the burning surface area receded, the heat release rate of the fire decreased and eventually the fire was suppressed. When the water application density was not high enough, not only the fire spread further in the flues, the fire also spread through the horizontal spaces between pallet loads of commodities toward the outside vertical surfaces of the fuel array. Eventually, the entire fuel array was involved in the fire. 
TABLE 1. TEST CONDITIONS AND VALUES OF $k$ AND $\Delta Q_{a} / \Delta Q_{a o}$ Total Heat Water Density
Release Rate Per Unit Exposed

Release Rate Per Unit Exposed
t Water Appli- Surface Area

$\begin{array}{cccccc}\text { Test Commodity } & \text { Fuel At Water Appli- } & \text { Surface Area } & \mathrm{k} & \\ \text { No. } & \text { Array } & \text { cation }(\mathrm{kW}) & \left(\mathrm{g} / \mathrm{m}^{2} / \mathrm{s}\right) & (\mathrm{sec})^{-1} & \frac{\Delta Q_{a}}{\Delta Q_{a O}}\end{array}$

\begin{tabular}{|c|c|c|c|c|c|c|}
\hline 28 & Plastic & $2 \times 2 \times 2$ & 7680 & 40.5 & 0.015180 & 0.124 \\
\hline 29 & Plastic & $2 \times 2 \times 2$ & 2790 & 32.0 & 0.006271 & 0.339 \\
\hline 32 & Class II & $2 \times 2 \times 2$ & 1100 & 8.9 & 0.000960 & 0.783 \\
\hline 33 & Class II & $2 \times 2 \times 4$ & 5000 & 22.6 & 0.008175 & 0.220 \\
\hline 34 & Class II & $2 \times 2 \times 4$ & 5430 & 17.9 & 0.004690 & 0.340 \\
\hline 38 & Plastic & $2 \times 2 \times 4$ & 5050 & 37.3 & 0.014820 & 0.200 \\
\hline 39 & Plastic & $2 \times 2 \times 4$ & 1650 & 31.1 & 0.014130 & 0.250 \\
\hline 46 & Plastic & $2 \times 2 \times 4$ & 3250 & 19.1 & -0.002070 & 0.700 \\
\hline 48 & Class II & $2 \times 2 \times 4$ & 2980 & 16.2 & 0.009314 & 0.230 \\
\hline 49 & Class II & $2 \times 2 \times 4$ & 3970 & 16.2 & 0.005624 & 0.480 \\
\hline 52 & Class II & $2 \times 2 \times 4$ & 1910 & 17.9 & 0.006858 & 0.450 \\
\hline 56 & Class II & $2 \times 2 \times 4$ & 5850 & 13.8 & 0.001062 & 0.610 \\
\hline 57 & Class II & $2 \times 2 \times 4$ & 3320 & 13.8 & 0.003396 & 0.550 \\
\hline 68 & Class II & $2 \times 2 \times 4$ & 3190 & 7.2 & -0.002904 & 1.019 \\
\hline 69 & Class II & $2 \times 2 \times 3$ & 5210 & 12.9 & 0.003042 & 0.646 \\
\hline 71 & Class II & $2 \times 2 \times 3$ & 2900 & 9.5 & 0.003090 & 0.574 \\
\hline 72 & Class II & $2 \times 2 \times 3$ & 2730 & 16.2 & 0.007346 & 0.279 \\
\hline 74 & Class II & $2 \times 2 \times 3$ & 5470 & 19.1 & 0.003264 & 0.513 \\
\hline 77 & Plastic & $2 \times 2 \times 2$ & 2560 & 24.4 & 0.004039 & 0.509 \\
\hline 79 & Plastic & $2 \times 2 \times 2$ & 3070 & 28.7 & 0.005907 & 0.384 \\
\hline 81 & Class II & $2 \times 2 \times 2$ & 2250 & 13.7 & 0.003225 & 0.484 \\
\hline 82 & Class II & $2 \times 2 \times 2$ & 5540 & 18.7 & 0.006887 & 0.364 \\
\hline 83 & Class II & $2 \times 2 \times 2$ & 2320 & 18.7 & 0.005525 & 0.360 \\
\hline 84 & Plastic & $2 \times 2 \times 2$ & 7810 & 35.3 & 0.006256 & 0.307 \\
\hline 85 & Plastic & $2 \times 2 \times 3$ & 2620 & 24.4 & 0.004045 & 0.532 \\
\hline 87 & Plastic & $2 \times 2 \times 3$ & 5230 & 24.4 & -0.001166 & 1.334 \\
\hline 90 & Plastic & $2 \times 2 \times 3$ & 2300 & 19.9 & 0.002819 & 0.625 \\
\hline 93 & Plastic & $2 \times 2 \times 3$ & 3120 & 16.9 & -0.001909 & 1.452 \\
\hline 99 & Plastic & $2 \times 2 \times 3$ & 2410 & 29.1 & 0.013830 & 0.155 \\
\hline 101 & Plastic & $2 \times 2 \times 3$ & 7500 & 26.7 & 0.007625 & 0.339 \\
\hline 106 & Plastic & $2 \times 2 \times 3$ & 2050 & 22.1 & 0.003862 & 0.518 \\
\hline 108 & Plastic & $2 \times 2 \times 4$ & 3300 & 16.9 & -0.003779 & 1.606 \\
\hline 109 & Plastic & $2 \times 2 \times 4$ & 3010 & 20.4 & -0.001453 & 1.078 \\
\hline 116 & Plastic & $2 \times 2 \times 4$ & 3260 & 26.3 & 0.010590 & 0.337 \\
\hline 117 & Plastic & $2 \times 2 \times 4$ & 2330 & 12.9 & -0.008666 & 2.663 \\
\hline 118 & Plastic & $2 \times 2 \times 4$ & 2670 & 16.9 & 0.000028 & 1.009 \\
\hline 119 & Plastic & $2 \times 2 \times 5$ & 7810 & 31.4 & -0.000603 & 1.280 \\
\hline 121 & Plastic & $2 \times 2 \times 5$ & 4140 & 25.5 & 0.002566 & 0.569 \\
\hline 122 & Plastic & $2 \times 2 \times 5$ & 2480 & 22.3 & 0.006775 & 0.510 \\
\hline 129 & Plastic & $2 \times 2 \times 5$ & 3740 & 19.4 & -0.001543 & 1.471 \\
\hline 130 & Plastic & $2 \times 2 \times 5$ & 3330 & 21.3 & 0.001285 & 0.908 \\
\hline 133 & Plastic & $2 \times 2 \times 5$ & 6600 & 23.1 & 0.004886 & 0.202 \\
\hline 137 & Plastic & $2 \times 2 \times 5$ & 1450 & 25.5 & 0.009533 & 0.290 \\
\hline 139 & Plastic & $2 \times 2 \times 5$ & 3870 & 27.4 & 0.008700 & 0.473 \\
\hline
\end{tabular}

Note: The ratio of $\Delta Q_{a} / \Delta Q_{a o}$ is for the period of 240 seconds after water application. 
The heat release rate of the fire equals the total burning rate of the fuel array multiplied by the heat of combustion. The total burning rate is the total rate of pyrolysis of the commodities stored in the rack, which depends on the energy balance between the heat flux received by the fuel surfaces from the flame and the heat absorbed by water due to evaporation. A governing equation describing the global energy balance can be expressed as:

$$
\frac{d}{d t}\left[V_{f} \rho_{f} C\left(T_{p}-T_{\infty}\right)\right]+\dot{m}_{f}^{\prime \prime} Q_{p} A=\beta \dot{m}_{f}^{\prime \prime} \Delta H_{c} A-\dot{m}_{e}^{\prime \prime} Q_{w} A
$$

where

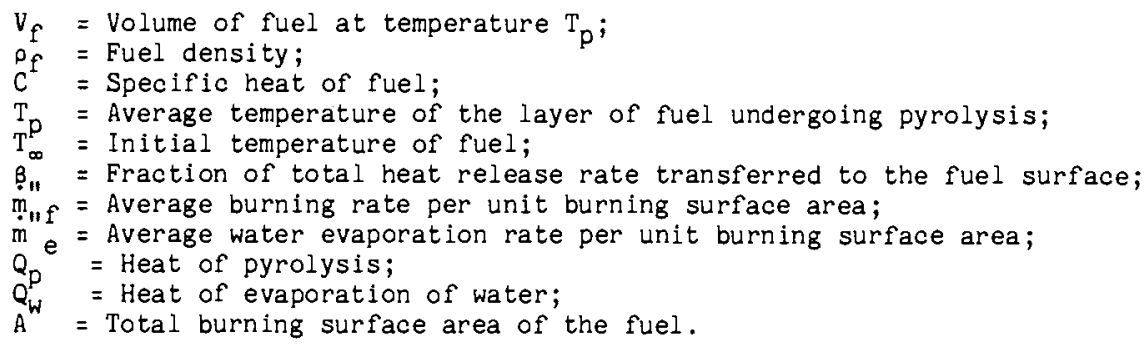

The first term in Eq. (1) represents the heat stored in the layer of fuel undergoing pyrolysis, and the second term represents the heat required for the pyralysis process in the fuel layer at temperature $T_{p}$. Eq. (1) has neglected the heat stored in the char and the virgin fuel behind the pyrolysis layer. $V_{f}$ may be expressed by $A \delta$, where $\delta$ is the average depth of fuel layer undergoing pyrolysis in a time period after water application. By defining a parameter $\alpha$ as the ratio of the total burning surface area versus the total volume of fuel under pyrolysis, $a$ can be approximated by $1 / \delta$. Assuming the thermal properties of the fuel, $\Delta \mathrm{H}_{C}, C$ and $\mathrm{T}_{\mathrm{p}}$ to be constants, Eq. (1) can be written in the following form:

$$
\frac{d A}{d t}+\frac{a\left(\dot{m}_{e}^{\prime \prime} Q_{w}-\beta \dot{m}_{f}^{\prime \prime} \Delta H_{c}+\dot{m}_{f}^{\prime \prime} Q_{p}\right)}{\rho_{f} C\left(T_{p}-T_{\infty}\right)} \quad A=0 .
$$

If $\dot{m}_{\mathrm{e}}^{\prime \prime}, \dot{m}_{f}^{\prime \prime}, \alpha$, and $\beta$ are representative averages in a time period for each test, Eq. (2) can be integrated to yield the following expression:

$$
\begin{aligned}
& A=A_{o} e^{-k\left(t-t_{o}\right)} \\
& \text { with } k=\frac{\alpha\left(\dot{\mathrm{m}}_{e} \mathrm{Q}_{w}-\beta \dot{\mathrm{m}}_{f}^{\prime \prime} \Delta \mathrm{H}_{c}+\dot{\mathrm{m}}_{f}^{\prime \prime} Q_{p}\right)}{\rho_{f} C\left(\mathrm{~T}_{p}-\mathrm{T}_{\infty}\right)},
\end{aligned}
$$

where $A_{0}$ is the area of fuel surface under pyrolysis at the time of water application, $t_{o}$. Since $\dot{Q}_{a}=A \dot{m}_{f} \Delta H_{c}$, we obtain the total heat release rate after water application:

$$
\dot{Q}_{a}=\dot{Q}_{a o} \exp \left[-k\left(t-t_{o}\right)\right]
$$

where $\dot{Q}_{a o}$ is the total heat release rate at the time of water application.

Equation (5) can be integrated to obtain the cumulative total heat release rate in a time period starting from water application: 


$$
\Delta Q_{a}=\dot{Q}_{a o} \quad\left(1-\exp \left[-k\left(t-t_{0}\right)\right]\right) / k \text {. }
$$

For the case in which the fire is suppressed, the heat release rate decreases with time after water application and $k$ should be a positive value. The asymptotic value of $\Delta Q_{a}$ for a positive $k$ is $\dot{Q}_{a} / k$ based on $E q$. (6). How ever, $\Delta Q_{a}$ cannot exceed the product of the fuel available at the beginning of water application and the heat of combustion. For the cases in which the fire is not suppressed, the heat release rate increases with time and eventually reaches a maximum value for a given fuel array. Therefore, Eq. (6) is expected to be valid only for a certain period of time after water application. For a period of time, $t-t_{0}$, we have

$$
\Delta Q_{a} / \Delta Q_{a 0}=\frac{1-\exp \left[-k\left(t-t_{0}\right)\right]}{k\left(t-t_{0}\right)}
$$

where

$$
\Delta Q_{\mathrm{a} o}=\dot{Q}_{\mathrm{a} o}\left(t-t_{0}\right) .
$$

In this study, the value of $k$ for each test (shown in Table 1) was obtained by least-square fitting the total heat release rate with respect to $\left(t-t_{0}\right)$ for a period of $240 \mathrm{~s}$ from water application.

In these tests, the water was appl ied from the top of the fuel array. The water densities per unit surface area shown in Table 1 were obtained by assuming that the water applied to the top of the fuel array is uniformly distributed to the exposed surfaces of the fuel array, i.e., the top surfaces of the commodities stored in the top tier and all original vertical surfaces of the commodities. If the water evaporation rate per unit burning surface area is assumed to be the same as the water application rate per unit surface area, Eq. (4) becomes:

$$
k=\frac{\alpha\left(\dot{m}_{w}^{\prime \prime} Q_{w}-\beta \ddot{m}_{f}^{\prime \prime} \Delta H_{c}+\ddot{m}_{f} Q_{p}\right)}{\rho_{f} C\left(T_{p}-T_{\infty}\right)}
$$

Figure 1 provides the plots of $k$ versus $\dot{m}_{W}^{\prime \prime}$ for the Standard Class II and Plastic commodities. Although there. ins considerable scattering of data, it appears that $k$ varies linearly with $\dot{\mathrm{m}}{ }_{\mathrm{w}}$. The data regressions shown in $\mathrm{Fig}$. 1 can be expressed by the following equations:

$$
\begin{aligned}
& \mathrm{k}=0.536 \dot{\mathrm{m}}_{\mathrm{w}}-0.0040 \\
& \left(\mathrm{sec}^{-1}\right)
\end{aligned}
$$
for the Standard Class II commodity in the range of $0.006<\dot{\mathrm{m}}_{\mathrm{w}}<0.024$
$\mathrm{~kg} / \mathrm{m}^{2} / \mathrm{s}$,

$$
\begin{aligned}
& \text { and } \mathrm{k}=0.716 \dot{\mathrm{m}}_{\mathrm{w}}-0.0131 \\
& \left(\mathrm{sec}^{-1}\right)
\end{aligned}
$$

for the Plastic commodity in the range of $0.012<\dot{m}_{w}<0.041 \mathrm{~kg} / \mathrm{m}^{2} / \mathrm{s}$. In deriving Eqs. (9) and (10), the ratio of the total burning surface area versus the total volume of fuel under pyrolysis has been approximated as a constant for each commodity investigated. It is expected that $\alpha$ also depends on the extent of the fire development at the time of water applica- 
tion. Since a has been approximated by an averaged value in the investigated period, this might have contributed to scattering of data in Eigure 1.

Based on Eqs. (8), (9) and (10), we have

$$
\begin{aligned}
& \frac{a Q_{W}}{o_{f} C\left(T_{p}-T_{s}\right)}=\left\{\begin{array}{l}
0.536 \text { for Class II Commodity } \\
0.716 \text { for Plastic Comodity }
\end{array}\right. \\
& \frac{a\left(\beta \dot{m}_{f}{ }^{\Delta H_{c}}-\dot{\mathrm{m}}_{\mathrm{f}}^{\prime \prime} \mathrm{Q}_{\mathrm{p}}\right)}{\rho_{\mathrm{f}} \mathrm{C}\left(\mathrm{T}_{\mathrm{p}}-\mathrm{T}_{\mathrm{s}}\right)}=\left\{\begin{array}{l}
0.00416 \text { for class I I Commodity } \\
0.01317 \text { for Plastic Commodity }
\end{array}\right.
\end{aligned}
$$

To obtain the value of a from $\mathrm{Eq}$. (11) we need to determine the properties of the tested commodities. The specific heat of the Class II commodity is taken as the mass-weighted value between the paper carton and the wood pallet. The specific heat of wood is estimated to be $1.3 \mathrm{~kJ} / \mathrm{kg} /{ }^{\circ} \mathrm{C}$, which represents the effective specific heat from virgin wood to char $(10)$. The specific heat of cellulose, $1.3 \mathrm{~kJ} / \mathrm{kg} /{ }^{\circ} \mathrm{C}(1)$ is used as the specific heat of the paper carton. The overall specific heat of the Class II commodity (excluding metal I iners) is therefore estimated to be $1.3 \mathrm{~kJ} / \mathrm{kg} /{ }^{\circ} \mathrm{C}$. With regard to the plastic commodity, the specific heat of polystyrene is around $1.34 \mathrm{~kJ} / \mathrm{kg} /{ }^{\circ} \mathrm{C}(12)$, and the mass-weighted specific heat of the Plastic commodity is calculated to be $1.32 \mathrm{~kJ} / \mathrm{kg} /{ }^{\circ} \mathrm{C}$. For gellulosic materials, pyrolysis takes place in the range of $300^{\circ} \mathrm{C}$ to $450^{\circ} \mathrm{C}(6,13)$. In this study, the average temperature of the layer of fuel under pyrolysis, $T_{\text {, }}$ of Class II commodity is selected to be $370^{\circ} \mathrm{C}$, around the mid-point of the pyrolysis temperature range. The ignition temperature of polystyrene has been reported to be also around $370^{\circ} \mathrm{C}(12)$. Therefore, $T_{p}$ of the Plastic commodity is taken to be $370^{\circ} \mathrm{C}$. The overali densities of $\mathrm{g}$ pallet load of the Class II commodity (combustibles alone) and Plastic commodity are $45.6 \mathrm{~kg} / \mathrm{m}^{3}$ and 57.0 $\mathrm{kg} / \mathrm{m}^{3}$, respectively.

With ambient temperature of $20^{\circ} \mathrm{C}$, the heat of evaporation of water being $2595 \mathrm{~kJ} / \mathrm{kg}$ and the properties of the Class II commodity presented above, the value of $\alpha$ in Eq. (11) is $4.291 / \mathrm{m}$. From Eq. (12) and $a=4.291 / \mathrm{m}$, we have

$$
B \dot{m}_{f}^{\prime \prime} \Delta H_{c}-\dot{m}_{f}^{\prime \prime} Q_{p}=20.1 \mathrm{~kW} / \mathrm{m}^{2}
$$

for the Class II commodity. Physically, $B \dot{m}_{f} \Delta H_{c}$ is the net heat flux from the fire to the fuel surface.

Similarly, the value of a for the Plastic commodity fuel array is calculated to be $7.271 / \mathrm{m}$ from Eq. (11), which is about $69 \%$ greater than the value a for the Class II commodity. For the Class II comnodity, the carton walls were backed with metal liner. As fire burned through a certain area of the carton walls of the Class II comodity, the original burning surface area remained about the same; whereas, for the Plastic commodity, the burning surface increased significantly as the fire burned through carton walls to expose cardboard dividers and the polystyrene cups. Therefore, the ratio a depends primarily on the packaging of the commodity. With $a=7.271 / \mathrm{m}$, we obta in

$$
\text { B } \dot{m}_{f}^{\prime \prime} \Delta H_{c}-\dot{m}_{f}^{\prime \prime} Q_{p}=47.8 \mathrm{~kW} / \mathrm{m}^{2}
$$

from Eq. (12) for the Plastic commodity. 
The values of $\beta$ and $\ddot{m}_{f}^{\prime \prime}$ in Eqs. (13) and (14) are interrelated. Neither of these two values was measured in the fire tests.

Based on Eqs. (4) and (7), for a commodity the ratio of the cumulative total heat release rate versus $\Delta Q_{a}$ in a time period after water application is only a function of $m$. Figure 2 presents such functional relationships for the Class II and the Plastic commodities. As expected, the $\Delta Q_{a}$ to $\Delta Q_{a}$ ratio increases as the water density decreases. We may define the critical application density as the density at which $\Delta Q_{a} / \Delta Q_{a 0}=1$. The lower graph in Figure 2 shows that $\Delta Q_{a} / \Delta Q_{a}$ varies moderately when the application density is much greater than the critical density. As the water application density decreases to the critical value and below, the ratio begins to increase rapidly. Overall, the Class II commodity requires less water than the Plastic commodity for the same degree of fire suppression results, i.e., for the same value of $\Delta Q_{a} / \Delta Q_{a o}$.

Based on the upper graph of Figure 2, the critical water density on the surface area exposed to water application for the Class II commodity is about $6 \mathrm{~g} / \mathrm{m}^{2} / \mathrm{s}$. As stated above, the critical water density defined in this paper is the density at which $\Delta Q_{a} / \Delta Q_{a O}=1$ only for a period of $240 \mathrm{~s}$ after water application. Heskestad $(3)$ defined a critical application density as the water application rate divided by the entire surface area of the fuel array, below such a rate fuel would be completely consumed. He reported the critical application density on the entire surface area for extinguishment of wood crib fires and wood pallet fires ranging from 1.5 to $3.0 \mathrm{~g} / \mathrm{m}^{2} / \mathrm{s}$. The ratio of the surface area exposed to water application defined in this study (the top surfaces plus all the vertical surfaces) versus the entire surface area, was about 0.55 for the cribs used in Refs. 5 and 6 . Therefore, the critical application densities reported by Heskestad for wood cribs and pallets were in the range of 2.7 to $5.5 \mathrm{~g} / \mathrm{m}^{2} / \mathrm{s}$, based on the surface area exposed to water application. For the plastic commodity, the critical water application density ranges from 17 to $20 \mathrm{~g} / \mathrm{m}^{2} / \mathrm{s}$ based on the lower graph of Fig. 2, which is greater than that of the Class II commodity. Heskestad also reported that critical water densities for wood cribs and wood pallet piles were greater than that for wood slabs $(3)$. It appears that the packaging and storage arrangement of a commodity, as well as the commodity type, has significant impact on the critical application density for fire suppression.

Figure 3 presents the ratio $\Delta Q_{a} / \Delta Q_{\text {ao }}$, which has been shown in $F$ ig. 2 , versus $k$ for both the Class II and the Plastic commodities stored in racks of different heights. The solid line shown in the figure represents the following equation:

$$
\Delta Q_{a} / \Delta Q_{a O}=[1-\exp (-240 \mathrm{k})] / 240 \mathrm{k},
$$

which is obtained from Eq. (7) with $t-t_{0}=240 \mathrm{~s}$.

Figure 3 demonstrates that the parameter $k$ correlates reasonably well with the fire suppression results of the two tested commodities in rack-storage arrangements.

\section{SUMMARY AND CONCLUSIONS}

A fire suppression parameter was identified to correlate the fire suppression results obtained from large-scale experiments conducted using two 
different commodities arranged in steel racks of different heights. The parameter is a function of fuel density, fuel specific heat, ignition temperature, heat of combustion, burning rate, heat of pyrolysis, and water application rate. The analysis presented in this paper can be used to determine the water application density required for achieving a desired fire suppression result. The commodity type, packaging and storage arrangement have significant influence on the magnitude of critical water application density for fire suppression.

\section{REFERENCES}

1. Yao, C., "FMRC Sprinkler Research, "Ninth Meeting of the United/Japan Panel on Fire Research and Safety, Tokyo, Japan, May, 1987.

2. Lee, J. L., "Suppression of Rack Storage Fires, Volume I-Measurements," FMRC Technical Report J.I. OG3E2. RA, Factory Mutual Research Corporation, Norwood, Massachusetts, 1984.

3. Heskestad, G., "The Role of Water in Suppression of Fire: A Review," Journal of Fire and Flammability, 11, pp. 254-262, 1980.

4. Rasbash, D. J., "The Extinction of Fire with Plain Water," The Proceedings of the First International Symposium of Fire Safety Science, Hemisphere Publishing Corporation, pp. 1145-1163, 1986.

5. Kung, $\mathrm{H}-\mathrm{C}$ and Hill J. P., "Extinction of Wood Crib and Pallet Fires," Combustion and Flame, 24, pp. 305-317, 1975.

6. Tamanini, F., "The Application of Water Sprays to the Extinguishment of Crib Fires," Combustion Science and Technology, 14, pp. 17-23, 1976.

7. Lee, J. L., "Extinguishment of Rack Storage Fires of Corrugated Cartons Using Water," The Proceedings of the First International Symposium of Fire Safety Science, Hemisphere Publishing Corp., 1986, pp. 1177-1186.

8. Heskestad, G., "A Fire Products Collector for Calorimetry into the MW Range," FMRC Technical Report J.I. OC2E1.RA, Factory Mutual Research Corporation, Norwood, Massachusetts, 1981.

9. Yu, H-Z, Lee, J.L. and Kung, H-C, "Suppression of Rack-Storage Fires by Water," FMRC Technical Report J.I. OQ3E8. RA, Factory Mutual Research Corporation, Norwood, Massachusetts, 1993.

10. Tamanini, F., "A Study of the Extinguishment of Vertical Wood Slabs in Self-Sustained Burning by Water Spray Application," Combustion Science and Technology, 14, pp. 1-5, 1976.

11. Drysdale, D., An Introduction to Fire Dynamics, John-Wiley \& Sons, 1985.

12. Thomson, H. E. and Drysdale, D. D., "Flammability of Plastics, I: Ignition Temperature, "Fire and Materials, 11, pp. 163-172, 1987.

13. Friedman, R., Principles of Fire Protection Chemistry, 2nd Ed., Chap. 8, National Fire Protection Association, 1989. 

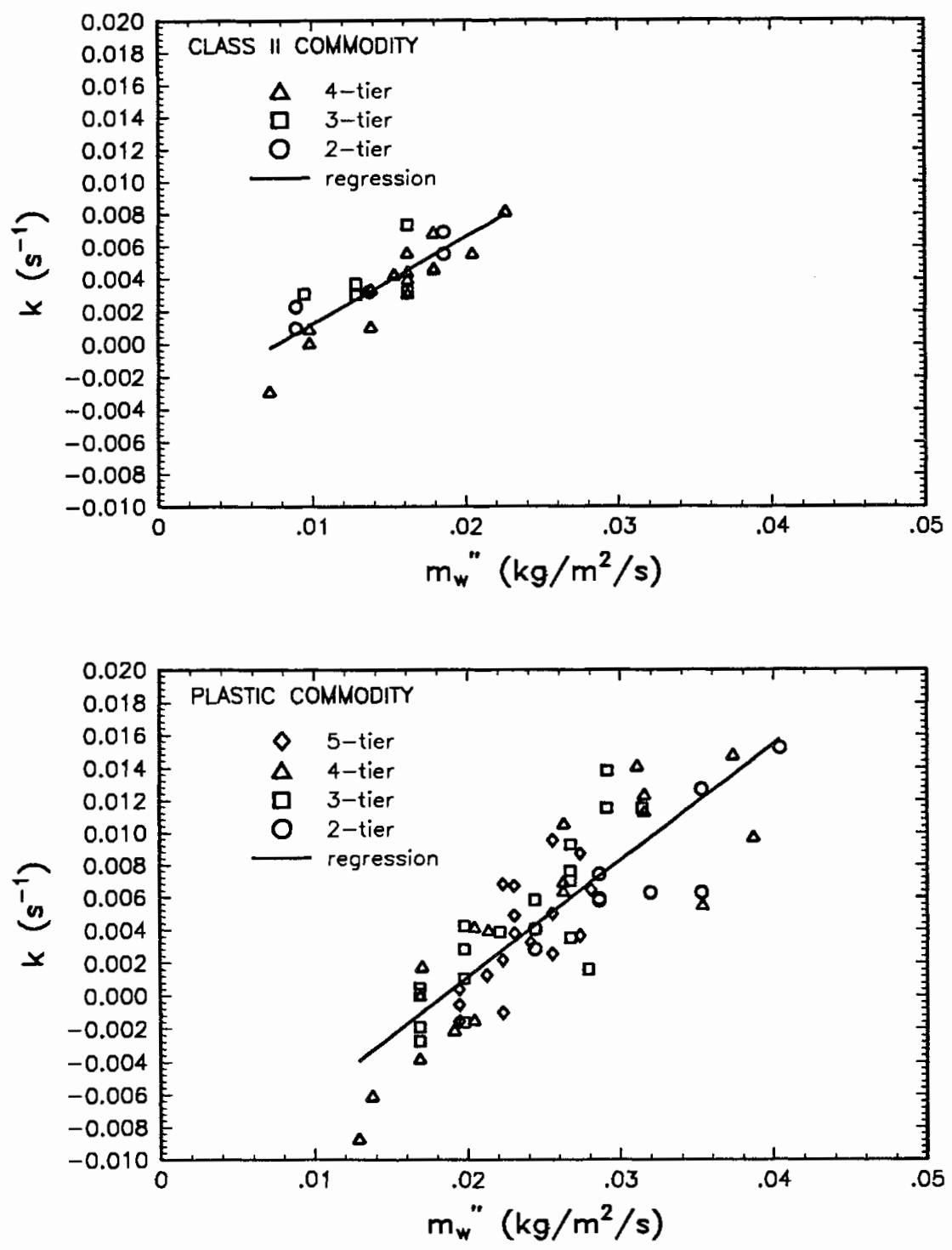

Figure 1. Correlations of $k$ versus Water Density on Fuel Surface. The upper graph is for the Class II Commodity, and the lower graph is for the Plastic Comodity. 

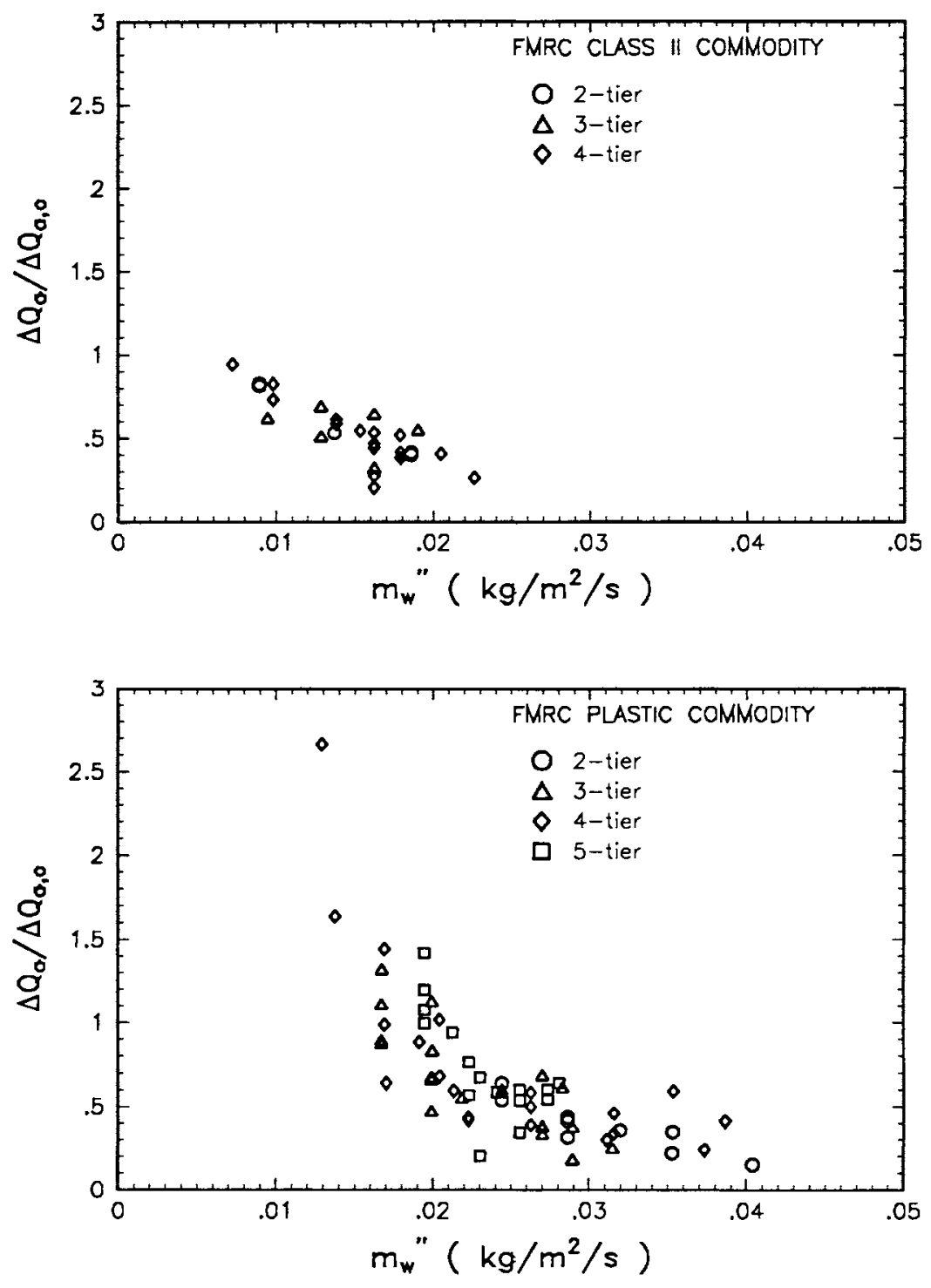

Figure 2. The variation of $\Delta Q_{a} / \Delta Q_{a O}$ with respect to $\dot{m}_{W}^{\prime \prime}$. The upper graph is for the Class II Commodity, and the lower graph is for the Plastic Commodity. 


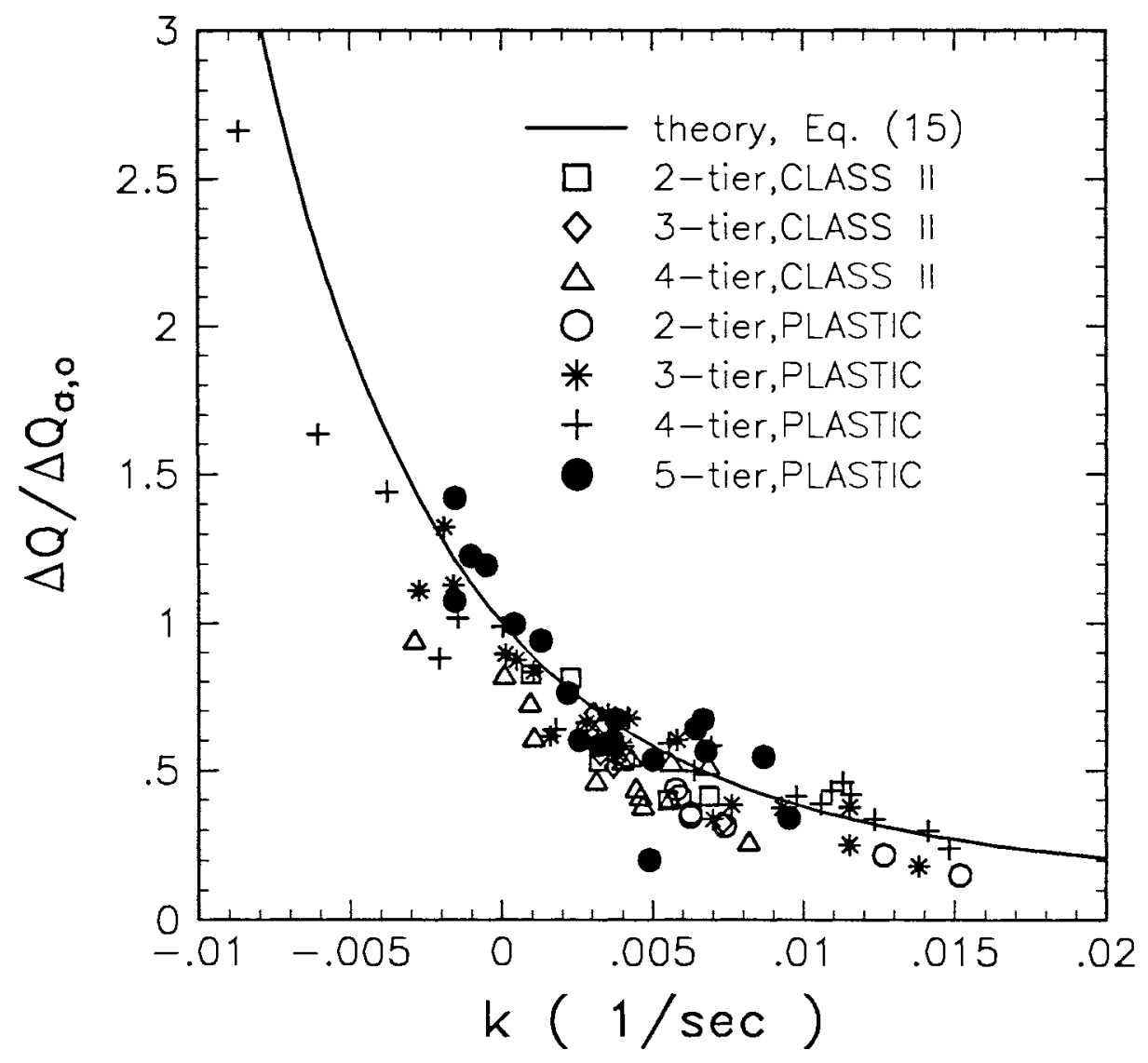

Figure 3. The Correlation of $\Delta Q_{a} / \Delta Q_{a o}$ versus $k$. 